\title{
I Coloquio de los Municipios Porfugueses
}

\author{
(LUANDA, 5 A 9 DE OCTUBRE DE 1963)
}

Por sugerencia del Gobernador general de Angola, la Cámara Municipal de Luanda, con el patrocinio del Ministerio del Interior y del de Ultramar, asumió la iniciativa de promover en dicha ciudad el I Coloquio Nacional de los Municipios Portugueses, con objeto de estrechar las relaciones entre los Municipios y promover el estudio de algunos de sus problemas fundamentales.

Los trabajos del Coloquio fueron distribuídos en cuatro Secciones, correspondiendo a cada una de ellas el estudio de las Comunicaciones referentes a los siguientes temas:

I. Reclutamiento y formación de los funcionarios municipales.

II. Los Municipios y el abastecimiento de las concentraciones urbanas (analizando el establecimiento de las formas más convenientes para la resolución del abastecimiento de las aglomeraciones urbanas, en -cuanto al suministro de agua potable, energía eléctrica, establecimiento de transportes colectivos, mercados y mataderos).

III. El ordenamiento urbanistico y la vida municipal (los procesos más adecuados de elaboración y ejecución de planes de urbanización).

IV. Intercambio entre los Municipios del mundo portugués (estre-chamiento de las relaciones entre los Municipios para procurarse directamente información sobre procesos de trabajo, cursos de formación -de funcionarios, cambio de informaciones, etc.).

El Coloquio fué solemnemente inaugurado en Luanda, el día 5 de octubre del año próximo pasado, por Su Excelencia el Presidente de la República, con la presencia del Ministro de Ultramar, Gobernador general de Angola, Director general de Administración Política y Civil del Ministerio del Interior $\mathrm{y}$ otras altas personalidades de la vida pública portuguesa.

Gran número de Municipios de todo el territorio portugués se haJlaban representados por sus delegaciones, pudiendo relacionarse Lisboa, 
Oporto, Coimbra, Braga, Beja, Braganza, Castelo Branco, Evora, Faro, Leiria, Santarem, Viana do Castelo, Villa Real, Viseu, Portalegre, Setúbal, Funchal, Punta Delgada, Angra do Heroísmo y Horta (de la Metrópoli); Praia (Provincia de Cabo Verde); Bissau y Bolama (Provincia de Guinea); Santo Tomé (Provincia de Santo Tomé y Príncipe); Luanda, Cabinda, Cubal, Benguela, Carmona, Dongo, Luso, Lobito, Moçâmedes, Nueva Lisboa, Sá de Bandeira, Villa General Machado, Santa Comba, Gabela, Salazar, S. Salvador, Serpa Pinto (Provincia de Angola); Lorenzo Marques, Beira, Nampula, Mozambique, Malange, Quelimane, Tete, Henrique Carvalho, Silva Porto, Porto Amelia (Provincia de Mozambique); Leal Senado de la Ciudad de Macao (Provincia de Macao); Dili (Provincia de Timor); Estado Portugués de la India (integrado en la delegación de Lisboa).

Fueron ampliamente discutidas más de veinte Comunicaciones sobre los temas indicados presentadas por las delegaciones de los Municipios participantes.

El 9 de octubre, en la sesión solemne de clausura de los trabajos del Coloquio, presidida por el Gobernador general de Angola, con asistencia, en lugar destacado, de Su Excelencia el Arzobispo coadjutor de Luanda, se procedió a la lectura de las Conclusiones, que fueron únánimemente aprobadas y pueden resumirse así:

- En Ultramar, en cada Provincia, convendría constituir un Cuerpo general de funcionarios municipales de categoría más elevada, sin perjuicio de la existencia de los Cuerpos privativos de cada autarquía;

- El mérito deberá ser la condición fundamental que se tenga en cuenta para el reclutamiento de los servidores municipales, cualquiera que sea su categoría;

- El reclutamiento de todo el personal de los Municipios deberá hacerse a través de concursos de habilitación;

- La conveniente formación profesional de los funcionarios municipales postula, como imperiosa necesidad, la existencia de un organismo en que se den cursos generales de habilitación y cursos de especialización, sin perjuicio de que los funcionarios municipales con funciones dirigentes tengan la preocupación de crear en sus subordinados el «espiritu de servicio» basado en el deseo de perfeccionamiento de los conocimientos técnicos, en la consciencia de la eficacia del trabajo en equipo y en el ideal de la persecución, en todas las circunstancias, del bien común del Municipio;

- Los servicios públicos que tengan carácter acentuadamente económico, y que, por tanto, hayan de ser organizados en forma de empresa 
industrial, se han de explotar, en principio, bajo la forma de municipalización, con autonomía administrativa y financiera (v. g. abastecimiento de agua y energía eléctrica y transportes colectivos);

- Los servicios públicos que atiendan intereses sanitarios deben ser explotados directamente por los Municipios (v. g. mataderos, mercados de abastos y de venta al detall, centrales pasteurizadoras o lecheras);

- La elaboración de los planes de urbanización de la circunscripción municipal deben ser estudiados en relación íntima con los planes regionales, teniéndose en consideración la planificación económica y social;

- Se aconsejarán medidas de carácter técnico-financiero y técnicoadministrativo, a fin de aumentar los rendimientos municipales, y la creación de servicios destinados a trabajos de urbanización, adoptándose el régimen de federación de Municipios cuando éstos, de por sí, no se hallen en condiciones de mantener tales servicios;

- Se recomienda que los administrados sean llamados a colaborar en la ejecución de la planificación urbana, sugiriéndose que los terrenos no aprovechados de acuerdo con los planes de urbanización sean sometidos a intensa tributación;

- Los Municipios portugueses deben cambiar entre sí toda clase de elementos e informaciones que interesen a la actividad municipal;

- Se considera de excepcional importancia la celebración de periódicos y frecuentes congresos, coloquios y reuniones de los Municipios portugueses, para el intercambio de ideas sobre la Administración municipal y reafirmación del espíritu de solidaridad y cohesión que es la base de la unidad nacional;

- Se acuerda elevar al Gobierno estas Conclusiones, a través de los Ministerios del Interior y Ultramar, para que sean consideradas en la medida que se juzgue conveniente y oportuno.

M. Caetano.

(Traducido por Gumersindo Guerra-Librero). 